\title{
Functional and Nonfunctional Parameters in Patients with Occupational Lung Diseases
}

\author{
PARASCHIVA POSTOLACHE ${ }^{\# \#, ~ M I H A E L A ~ M O S C A L U 2 *, ~ A L I N A ~ C R O I T O R U ~}{ }^{3 *}$, GABRIELA JIMBOREAN ${ }^{4}$ \\ ${ }^{1}$ Grigore T. Popa University of Medicine and Pharmacy, Faculty of Medicine, Ist Medical Department, Respiratory \\ Rehabilitation Clinic, 16 Universitatii Str., 700115, Iasi, Romania \\ ${ }^{2}$ Grigore T. Popa University of Medicine and Pharmacy, Faculty of Medicine, Preventive Medicine and Interdisciplinarity \\ Department, 16 Universitatii Str., 700115, lasi, Romania \\ ${ }^{3}$ Carol Davila University of Medicine and Pharmacy, Department of Pneumology, 37 Dionisie Lupu Str. , Bucharest, Romania \\ ${ }^{4}$ University of Medicine and Pharmacy, Clinic of Pulmonology, 5 Gh. Marinescu Str., 540142, Tirgu Mures, Romania
}

\begin{abstract}
Patients with occupational lung diseases (OLD) may present respiratory functional impairment, exertional dyspnea and decreased exercise tolerance. These factors lead to reduced daily physical activity, social isolation, decreased quality of life (QoL) and depression. Assessment of respiratory functional status in patients with OLD in correlation with the presence of anxiety and depression and the quality of life in patients with OLD, as extrapulmonary comorbidities. In patients with diagnosed OLD, the following parameters were evaluated: pulmonary function tests (FEV1, FVC), anxiety and depression with Hospital Anxiety and Depression Scale (HADS), and QoL by St George Respiratory Questionnaire (SGRQ). 46 nonsmoking patients (9 females) were included in this study: occupational asthma (10), occupational COPD (20), pneumoconiosis (16). Mean aged 58.98 11.84 SD years old. Anxiety and depression were present in 35 patients (76.08\%). Mean HADS score was 14.3 points $\pm .25 S D$, and a severe psychological impairment (HADS > 16) was found in 16 cases (34.8\%). The highest incidence of anxiety and depression was found in COPD (85\%, mean HADS score 16.05 points $\pm 8.18 \mathrm{SD}$ ), followed by pneumoconiosis (75\%, mean HADS 13.5 points $\pm 6.875 D)$ and $O A(60 \%$, mean HADS score 12.2 points $\pm 5.45 S D)$. The QoL was affected in all patients, with a mean SGRQ score of 52.7 points $\pm 16.1 S D$; the most affected was the activity domain. In patients with OLD, extrapulmonary manifestations may be encountered, such as anxiety, depression and ultimately impaired QoL. This may indicate that treatment of these patients should be multidisciplinary, including psychosocial support.
\end{abstract}

Keywords: occupational lung disease, anxiety, depression, pulmonary function test, quality of life

Anxiety and depression represents significant comorbidities in respiratory diseases, reaching 30 to $50 \%$ of COPD patients. It is related to different factors, such as respiratory symptoms, impaired exercise capacity, chronic evolution of the disease, treatment demands and social isolation [1-3].

The presence of anxiety and depression can lead to severe consequences as longer hospitalization and poor survival. The depressed patients may experience increased symptom burden, impaired social functioning which lead to a vicious circle and finally to impaired quality of life $[4,5]$.

The aim of this study was to assessment of respiratory functional status in patients with OLD in correlation with the presence of anxiety and depression and the quality of life in patients with OLD, as extrapulmonary comorbidities.

\section{Experimental part}

Materials and methods

The subjects were selected from consecutive patients with occupational lung diseases, addressed for evaluation to a pneumology department. Before entering in the study, all of them signed an informed consent to allow using the medical information.

All patients were previously diagnosed with occupational lung disease. Occupational asthma (OA) was defined by reversible airflow obstruction and hyper responsiveness due to a particular exposure in the workplace [22-23]. Occupational COPD referred to an airflow limitation that was not fully reversible, in patients with history of occupational exposure [10]. The pneumoconiosis diagnostic was made based on exposure to inhalation of dust, restrictive lung function and characteristic radiologic aspect (e.g. nodules, reticulonodular opacities, eggshell calcification). Exclusion criteria of our study was: the presence of smoking (current or former), mental diseases, the personal history of anxiety and depression.

In the subjects of our study we assessed the quality of life by using George's Respiratory Questionnaire (SGRQ) and the anxiety and depression by using Hospital Anxiety and Depression scale (HADS).

The St George's Respiratory Questionnaire (SGRQ) is a tool used to assess quality of life and it is specific for respiratory diseases. Itis a self-administrated questionnaire that contains three domains (symptoms, activity and impact) and a total score. The score can range from 0-100 points, with higher scores indicating a worse health status [6]. We used the validated Romanian version for this study.

Hospital Anxiety and Depression scale (HADS) is an instrument used to assess anxiety and depression. It is a self-reported questionnaire, fulfilled by the patients. The questionnaire contains two parts and 14 items ( 7 questions related to anxiety and 7 questions related to depression). The score range is $0-21$ points. $A$ score $\geq 8$ on either part = cut-off point for anxiety and depression.

The other parameters registered were:

Pulmonary function tests: the FEV1, FVC were measured 15-30 minutes after inhalation of 400 mcg salbutamol. There were at least 3 measures who met the criteria for acceptability and repeatability. We chose the higher value. 
Dyspnea was assessed by modified Medical Research Council mMRC dyspnea scale. The scale has 5 degrees, that can range from 0 to 4, 4 being the greatest level of breathless.

\section{Statistical Analysis}

Statistical analysis was performed using IBM SPSS Statistics 22.0. The results were expressed as mean value \pm standard deviation. The statistical data analysis was performed through the ANOVA and Kruskal-Wallis test; the determination of the confidence interval $(\mathrm{Cl})$ and the $\chi^{2}$ test. $A p$ value $<0.05$ was considered significant.

\section{Results and discussions}

There were 46 patients, 9 females and 37 males (table 1 ). Mean age was 58.98 years old. The occupational respiratory disease was: asthma (10 cases), COPD (20 cases), pneumoconiosis (16 cases).

In the whole group of patients with OLD, HADS score has a mean value of 14.3 points and was correlated with dyspnea level measured on mMRC scale $(r=0.512$, $\mathrm{p}<<0.01,95 \% \mathrm{Cl}$ ) (fig.1).

The presence of anxiety and depression was considered when the patients had a HADS score $>=8$, which was the case of 35 patients ( $76 \%$ cases). Among this, 16 patients

Table 1

THE CHARACTERISTICS OF PATIENTS WITH OCCUPATIONAL LUNG DISEASES AND WITH PNEUMOCONIOSIS, COPD AND ASTHMA

\begin{tabular}{|c|c|c|c|c|c|}
\hline \multirow[b]{2}{*}{ Patients characteristics } & \multirow[b]{2}{*}{$N=46$} & \multicolumn{3}{|c|}{ Occupational disease } & \multirow[b]{2}{*}{$\begin{array}{l}\text { p-value } \\
(95 \% \mathrm{CI})\end{array}$} \\
\hline & & $\begin{array}{l}\text { Asthma } \\
\mathbf{n}=10\end{array}$ & $\begin{array}{l}\text { COPD } \\
\mathbf{n}=\mathbf{2 0}\end{array}$ & $\begin{array}{l}\text { Pneumoconiosis } \\
\mathbf{n}=16\end{array}$ & \\
\hline Age (years) & $58.98 \pm 11.8$ & $57.9 \pm 4.9$ & $58.2 \pm 12.4$ & $60.7 \pm 14.4$ & $\mathrm{p}=0.781$ \\
\hline \multicolumn{6}{|l|}{ Sex } \\
\hline females & $9(19.6 \%)$ & $5(31.3 \%)$ & $1(5 \%)$ & $3(30 \%)$ & $\mathrm{p}=0.065$ \\
\hline males & $37(80.4 \%)$ & $11(68.8 \%)$ & $19(95 \%)$ & $7(70 \%)$ & \\
\hline $\mathrm{BMI}\left(\mathrm{kg} / \mathrm{m}^{2}\right)$ & $27.56 \pm 5.9$ & $27.04 \pm 4.9$ & $26.7 \pm 4.9$ & $28.9 \pm 7.5$ & $\mathrm{p}=0.514$ \\
\hline FEV1 (1) & $1.23=0.48$ & $1.04 \pm 0.58$ & $1.19 \pm 0.36$ & $1.39 \pm 0.53$ & $\mathrm{p}=0.178$ \\
\hline FEV1 ( $\%$ predicted) & $41.75 \pm 16.06$ & $37.9 \pm 16.7$ & $37.11 \pm 10.94$ & $49.97 \pm 18.56$ & $\mathrm{p}=0.0363^{\text {i }}$ \\
\hline FVC (1) & $2.34 \pm 0.72$ & $2.52 \pm 0.81$ & $2.26 \pm 0.67$ & $2.26 \pm 0.69$ & $\mathrm{p}=0.316$ \\
\hline FVC ( $\%$ predicted) & $60.3 \pm 13.9$ & $58.98 \pm 14.3$ & $61.98 \pm 13.28$ & $59.13 \pm 15.14$ & $\mathrm{p}=0.789$ \\
\hline FEV1 / FVC ratio & $52.68 \pm 13.7$ & $49.5 \pm 11.5$ & $46.79 \pm 7.32$ & $62.66 \pm 16.38$ & $\mathrm{p}=0.0042^{*}$ \\
\hline $\mathrm{SaO} 2 \%$ & $93.7 \pm 4.27$ & $93.7 \pm 2.4$ & $92.9 \pm 3.87$ & $92.69 \pm 5.64$ & $\mathrm{p}=0.953$ \\
\hline Dyspnea ( mMRC) & $2.8 \pm 0.68$ & $2.6 \pm 0.69$ & $2.85 \pm 0.75$ & $2.88 \pm 0.61$ & $\mathrm{p}=0.735$ \\
\hline HADS score (points) & $14.33 \pm 7.25$ & $12.2 \pm 5.45$ & $16.05 \pm 8.18$ & $13.5 \pm 6.87$ & $\mathrm{p}=0.532$ \\
\hline SGRQ - total (points) & $52.76 \pm 16$ & $59.5 \pm 20$ & $48.81 \pm 13$ & $53.48 \pm 15$ & $\mathrm{p}=0.210$ \\
\hline SGRQ - symptoms & $53.24 \pm 21.4$ & $63.76 \pm 17.4$ & $46.42 \pm 22.2$ & $55.19 \pm 20.8$ & $\mathrm{p}=0.077$ \\
\hline SGRQ - activity & $69.64 \pm 20.7$ & $73.74 \pm 26.4$ & $65.39 \pm 18.4$ & $72.39 \pm 19.9$ & $\mathrm{p}=0.200$ \\
\hline SGRQ - impact & $41.4 \pm 19.3$ & $45.7 \pm 26.9$ & $39.35 \pm 15.6$ & $41.31 \pm 18.7$ & $\mathrm{p}=0.868$ \\
\hline \multicolumn{6}{|c|}{$\begin{array}{l}\text { Values were expressed as number (\%) mean } \pm \text { SD or percent at } \% \text {; } \\
\left({ }^{*}\right) \text { Marked effects are significant at } p<.05 \text {, Statistical test }-95 \% \mathrm{CI} \text { (Confidence Interval) }\end{array}$} \\
\hline
\end{tabular}




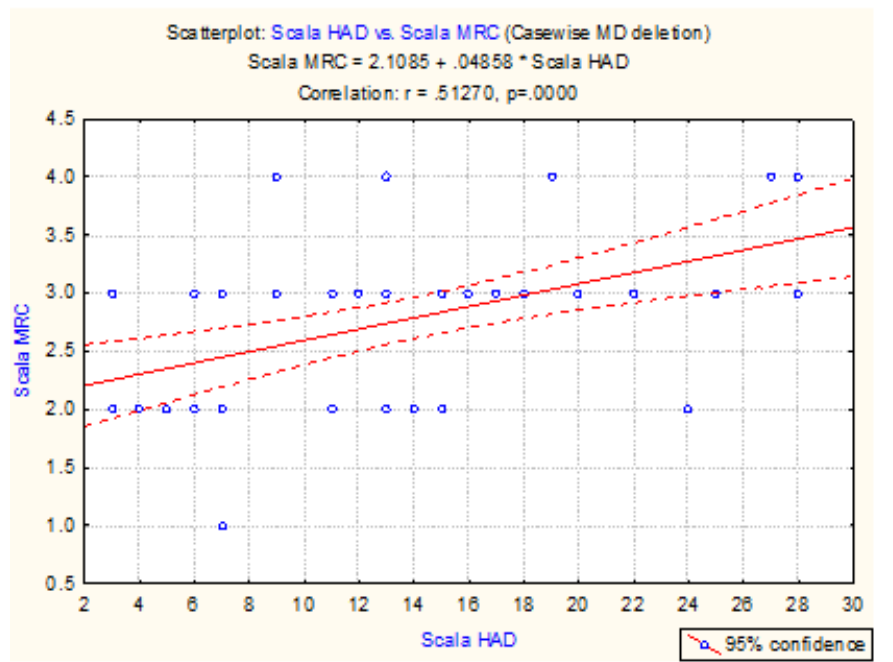

Fig. 1. Correlation HADS vs MRC DYSPNEA

( $34 \%$ cases) had a severe mood disorder, indicated by a HADS score greater than 16 (table 2).

When the presence of these comorbidities was analysed in different occupational diseases, we see that occupational COPD patients had the higher occurrence of psychological symptoms (85\% of total COPD cases). 12 patients with pneumoconiosis $(75 \%$ of total pneumoconiosis cases) and 6 patients with occupational asthma ( $60 \%$ of asthma cases) experienced also anxiety and depression (table 3 ).

When the comparative analysis was made between the three groups of patients (with asthma, COPD and pneumoconiosis, table 3) we noticed that the HADS has higher values in patients with COPD and asthma (mean value of 16 points) than in fibrotic lung disease.

Regarding the other main parameter evaluated, the quality of life has been affected in all cases, with a mean SGRQ score of 52.76 points, the most affected patients being the ones with asthma, followed by the ones with pneumoconiosis and COPD. The most significant impact for all the OLD patients was in the activity domain, followed by the symptoms and impact domain (table 1 ).

Anxiety and depression are significant comorbidities in respiratory pathology, with significant impact in the quality of life and social functioning of the patients, mortality and hospitalizations [1-6].

Table 2

THE HADS SCORE INTERVALS AND EACH CORRESPONDING NUMBER OF PATIENTS

\begin{tabular}{|l|c|c|c|}
\hline & Normal & Moderate & Severe \\
\hline HADS score (points) & $<8$ & $8-16$ & $>16$ \\
\hline Patients nr (\% total) & $11(24 \%)$ & $19(41 \%)$ & $16(35 \%)$ \\
\hline
\end{tabular}

\begin{tabular}{|l|c|c|c|}
\hline & COPD & Asthma & Pneumoconiosis \\
\hline Patients (nr) & 20 & 10 & 16 \\
\hline Patients with anxiety and & $17(85 \%)$ & $6(60 \%)$ & $12(75 \%)$ \\
depression -nr (\% total) & & & \\
\hline Pearson Chi-square test- Yates Chi-square $(n<5) \cdot 95 \% \mathrm{Cl}^{-} \gamma^{2}=\mathbf{2 . 2 4} p=\mathbf{3 2 5}$ \\
\hline
\end{tabular}

Pearson Chi-square test; Yates Chi-square $(n<5) ; 95 \% \mathrm{CI}: \chi^{2}=2.24, p=.325$
The literature data showed that approximately 15\% of COPD is work-related and that new agents causing COPD, as well as new cases with persistent airflow limitation associated with work are still reported [10]. It is known that in general, there is a report of higher incidence of anxiety and depression in patients with COPD than in general population. The reasons are chronic and progressive appearance of the disease, dyspnea, treatment requirements, unpredictable nature of exacerbations and the consequences on everyday life $[5,25]$. There is a vicious circle in which dyspnea leading to fear of physical exercise could cause shortness of breath.

In our study, the presence of anxiety and depression has the highest incidence in patients with occupational COPD ( $85 \%$ cases), with a mean HADS score of 16 points, expression of a severe mood impairment.

Specific multidisciplinary therapy, as pulmonary rehabilitation, may improve the psychological status and the quality of life in occupational COPD $[7-9,24]$.

In our patients with pneumoconiosis, the symptoms of anxiety and depression were found in $75 \%$ cases, with a mean HADS score lower than in the two other analysed groups: 13.5 points. Previous studies have shown that these psychological symptoms are present in 30-50\% of patients with fibrotic pulmonary disease, associated with dyspnoea and other measures of fibrosis severity, being a predictor of quality of life [11-14]. Studies on other fibrotic occupational lung diseases as silicosis showed the presence of the anxiety and depression that can affect quality of life [15]. Han conducted a study on 324 silicosis patients and found out that $99.1 \%$ had anxiety symptoms and $86.1 \%$ depression symptoms [16]. Meanwhile, the social support significantly influenced symptoms of anxiety and depression.

In the pneumoconiosis group of patients we found a significant impairment of the quality of life, especially with impact in the activity of the daily life (SGRQ activity score 72.39 points).

Another target population of our study were the subjects with occupational asthma, in which we found that anxiety and depression occurred in $60 \%$ of patients. Indeed, Leander study showed on 2270 patients with asthma that HADS score was the most important determinant for night symptoms and dyspnoea crisis, concluding that there is a strong association between respiratory symptoms and psychological status [19].

In asthma, the presence of anxiety and depression lead to poor asthma control. A study that investigates the factors related to poor asthma control in the workers exposed to World Trade Centre attacks showed that participants who had impaired mental health had the chances of poor control 5 times higher and of very poor control 13 times higher compared to participants without mental health comorbidities [18]. Disease management in these particular cases should include psychological treatment.
Table 3

PRESENCE OF ANXIETY AND DEPRESSION (HADS SCORE $\geq 8$ ) IN DIFFERENT RESPIRATORY DISEASES 
Patients with occupational asthma may also have impaired quality of life related to psychological distress [20]. In 40 patients with $O A$, who have been followed 2 years after exposure cessation, Yakoub found out that quality of life was moderately affected and there was a prevalence of depression and anxiety close to $50 \%$ [21].

In most of our patients affected by a negative change in mood, the impairment was very severe: high HADS score in 16 patients from 46. It may be explained by the failure of medical treatment to improve symptoms and quality of life, social isolation.

Another observation is that the HADS score was higher in asthma and COPD groups than in the pneumoconiosis. As the dyspnoea level is similar in the 3 groups, it may be related to the functional status, more affected in asthma and COPD, in addition to other non-functional factors.

Therefore, adding counselling programs to medical treatment may improve mental status and quality of life more than the treatmentalone. The psychological therapy doesn't target only the patient, but also people around him (family, friends). Psychological counselling should allow the patients to identify their needs and the obstacles they face, to be able to generate solutions and to bring the behavioural changes to enable better management of the disease in daily life, to set their short and long term objectives.

We find interesting that all patients had impaired quality of life, regardless of the psychological status. This is caused by the presence of respiratory symptoms and the impaired daily activity and functional status. This is an argument that occupational lung diseases must be regarded as being much complex, with associated comorbidities and the treatment must be complex.

\section{Conclusions}

In patients with occupational lung diseases, extra pulmonary manifestations such as anxiety and depression may be encountered and ultimately impaired quality of life. This may indicate that treatment of these patients should be multidisciplinary, including psychosocial support. Interventions that reduce anxiety and depression may improve the evolution of respiratory diseases.

\section{References}

1.KUNIK, ME., ROUNDY, K., VEAZEY, C., SOUCHEK, J ., RICHARDSON, P., WRAY, NP., STANLEY, MA. Surprisingly high prevalence of anxiety and depression in chronic breathing disorders. Chest. 2005 Apr; 127(4), p.1205-11.

2.MIKKELSEN, RL., MIDDELBOE, T., PISINGER, C., STAGE, KB. Anxiety and depression in patients with chronic obstructive pulmonary disease (COPD). A review. Nord J Psychiatry. 2004;58(1), p. 65-70.

3.NG, TP., NITI, M., TAN, WC., CAO, Z., ONG, KC., ENG, P. Depressive symptoms and chronic obstructive pulmonary disease: effect on mortality, hospital readmission, symptom burden, functional status, and quality of life. Arch Intern Med. 2007 J an 8;167(1), p.60-7.

4. PUMAR, MI., GRAY, CR., WALSH, JR., YANG, IA., ROLLS, TA., WARD, $\mathrm{DL}$. Anxiety and depression-Important psychological comorbidities of COPD. Thorac Dis. 2014 Nov; 6(11), p.1615-31.

5.POSTOLACHE, P., COSTIN, M., DUMBRAVA, EL., COJOCARU, DC. Anxiety and Depression in Patients with Chronic Obstructive Pulmonary Disease: an Open Agenda for Research. Rev Med Chir Soc Med Nat lasi, 2014 J an-Mar; 118 (1), p 39-44.

6.J ONES, P. St. George's Respiratory Questionnaire Manual. Version 2.3(2009).

7.POSTOLACHE, P., COJOCARU, DC. Pulmonary Rehabilitation - From Guidelines to Practice. Rev Med Chir Soc Med Nat lasi, 2013 Apr-Jun; 117 (2), p.380-7.
8.CROITORU, A., IONITA, D., STROESCU, C., PELE, I., GOLOGANU, D., DUMITRESCU, A., MARINESCU, L., ANGHELESCU, D., BOGDAN, MA. Benefits of a 7-Week Outpatient Pulmonary Rehabilitation Program in COPD Patients. Pneumologia, 2013 Mar-Jun, 62 (2), p. 94-8,101.

9.POSTOLACHE, P., NEMES, RM., CROITORU, A., CONSTANTIN, B. The role of pulmonary rehabilitation in occupational COPD. JEPE Vol. 16, No.2 (2015), p. 521-527.

10.BOSCHETTO, P., QUINTAVALLE, S., MIOTTO, D., LO CASCIO, N., ZENI, E., MAPP, CE. Chronic obstructive pulmonary disease (COPD) and occupational exposures. J Occup Med Toxicol. 2006; 1: 11.

11.HOLLAND, AE., FIORE, JF JR., BELL, EC., et al. Dyspnoea and comorbidity contribute to anxiety and depression in interstitial lung disease. Respirology. 2014;19(8), p.1215-1221.

12.RYERSON, CJ., BERKELEY, J., CARRIERI-KOHLMAN, VL., PANTILAT, SZ.,LANDEFELD, CS., COLLARD, HR. Depression and functional status are strongly associated with dyspnea in interstitial lung disease. Chest. 2011;139(3), p.609-616.

13.AKHTAR, AA., ALI, MA., SMITH, RP. Depression in patients with idiopathic pulmonary fibrosis. Chron Respir Dis. 2013;10(3), p.127133.

14.FULTON, BG., RYERSON, CJ. Managing comorbidities in idiopathic pulmonary fibrosis. Int J Gen Med. 2015 Sep 22;8, p.309-18.

15.YILDIZ, T., ETSSIZOGLU, A., ONAL, S., ATES, G., AKYILDIZ, L., YASAN, A., OZMEN, CA., CIMRIN, AH. Quality of life, depression and anxiety in young male patients with silicosis due to denim sandblasting. Tuberk Toraks. 2011;59(2), p.120-5.

16.HAN, B., YAN, B., ZHANG, J., ZHAO, N., SUN, J., LI, C., LEI, X., LIU, $H$., CHEN, J. The influence of the social support on symptoms of anxiety and depression among patients with silicosis. Scientific World J ournal. 2014; 2014:724804.

17.TARLO, SM., BALMES, J., BALKISSOON, R., BEACH, J., BECKETT, W., BERNSTEIN, D., BLANC, PD., BROOKS, SM., COWL, CT., DAROOWALLA, F., HARBER, P., LEMIERE, C., LISS, GM., PACHECO, KA., REDLICH, CA., ROWE, B., HEITZER, J. Diagnosis and management of work-related asthma: American College Of Chest Physicians Consensus Statement. Chest. 2008;134(3 Suppl):1S.

18.J ORDAN, HT., STELLMAN, SD., REIBMAN, J., FARFEL, MR., BRACKBILL, RM., FRIEDMAN, SM., LI, J., CONE, JE. Factors associated with poor control of 9/11-related asthma 10-11 years after the 2001 World Trade Center terrorist attacks. J Asthma. 2015;52(6), p.630-7.

19.LEANDER, M., LAMPA, E., RASK-ANDERSEN, A., FRANKLIN, K., GISLASON, T., OUDIN, A., SVANES, C., TOREN, K., JANSON, C. Impact of anxiety and depression on respiratory symptoms. Respir Med. 2014 Nov; 108(11), p.1594-600.

20.MIEDINGER, D., LAVOIE, KL., L'ARCHEVEQUE, J., GHEZZO, H., MALO, JL. Identification of clinically significant psychological distress and psychiatric morbidity by examining quality of life in subjects with occupational asthma. Health Qual Life Outcomes. 2011 Sep 22;9:76. 21.YACOUB, MR., LAVOIE, K., LACOSTE, G., DAIGLE, S., L'ARCHEVÊQUE, J., GHEZZO, H., LEMIERE, C., MALO, JL. Assessment of impairment/disability due to occupational asthma through a multidimensional approach. Eur Respir J. 2007 May;29(5), p.889-96.

22.TARLO, SM., LEMIERE, C. Occupational asthma. N Engl J Med. 2014 Feb;370(7), p.640-9.

23.CONSTANTIN, B., POSTOLACHE, P., CROITORU, A., NEMES, RM. Occupational Bronchial Asthma - Clinical and Epidemiological Aspects. JEPE Vol. 16, No.2 (2015),p. 517-520.

24.POSTOLACHE, P., POP, CS., NEMES, RM., NITU, FM. Pulmonary Rehabilitation in COPD. Archives of the Balkan Medical Union, June 2015, 50(2), p. 262-267.

25.POSTOLACHE, P., NEMES, RM., COJOCARU, DC. Progressive Dyspnea - Comprehensive Evaluation of a Common Symptom. Rev Med Chir Soc Med Nat lasi, 2014, 118(3), p. 649-653.

$\overline{\text { Manuscript received: } 19.03 .2017}$ 